\title{
LOS ORÍGENES DE LO HUMANO. EL MÉTODO GENÉTICO DE GIAMBATTISTA VICO ${ }^{1}$
}

\author{
ANNA MARIA BRIGANTE ROVIDA \\ Pontificia Universidad Javeriana, Bogotá
}

\begin{abstract}
RESUMEN: Este artículo se propone explicar el método genético de Vico como una dialéctica entre una filología que amplía su espectro en razón de una novedosa concepción de la relación entre oralidad y escritura, y una filosofía que se concibe como una metafísica de la mente. La articulación entre estas disciplinas le permite al autor acceder a los orígenes de lo humano y, al mismo tiempo, llevar a cabo una crítica a la racionalidad moderna que ha hecho patente su incapacidad de interpretar la mentalidad de los primeros pobladores. La exigencia de Vico, entonces, es la de afinar y ajustar el modo de comprensión de los remotos orígenes y dar cuenta de la complejidad de lo humano y su dimensión histórica sin renunciar a configurar una ciencia.
\end{abstract}

PALABRAS CLAVE: origen; humano; filología; racionalidad; oralidad; escritura.

\section{The Origins of the Human. The Genetic Method of Giambattista Vico}

ABSTRACT: This article explains the genetic method of Vico as a dialectic between two elements: on the one hand, a philology that expands its reach due to a novel conception of the relation between orality and writing; and, on the other, a philosophy that is conceived as a metaphysics of the mind. The articulation between these disciplines allows the author to access the origins of the human, while simultaneously performing a critique of modern rationality, which has evinced its incapacity to interpret the mentality of the first settlers. Vico's challenge is thus to refine and adjust the mode of comprehension of our remote origins, and to account for the complexity of the human and its historic dimension, without sacrificing the configuration of a science.

KEY WORDS: origin; human; philology; rationality; orality; writing.

En los Principios de ciencia nueva Vico se propone, parafraseando el subtítulo de su obra, establecer los principios en torno a la naturaleza común de las naciones. Con naturaleza de una nación se refiere a "su crecimiento en cierto tiempo y con ciertas circunstancias, las cuales siempre que son tales, así y no otras nacen las cosas»²; en este sentido, la indagación viquiana va dirigida al desarrollo histórico de las naciones, es decir, de las colectividades humanas que tienen todas una naturaleza común; en otras palabras, la atención del autor se enfoca en el mundo civil «que ha sido hecho ciertamente por los hombres»³. Según dice Lollini, este axioma demuestra, como numerosos comentaristas han

1 En este artículo se va a usar la traducción de Rocío de la Villa de Tecnos del 2006. Se citará el parágrafo correspondiente a cada cita, esto en razón de que no hay traducción al español con la paginación al margen de la edición italiana del 2012, editada por Manuela Sanna y Vincenzo Vitiello en Bompiani: La Scienza nuova. Le tre edizioni del 1725, 1730 e 1744. La Ciencia nueva se citará utilizando la abreviatura SN y el correspondiente párrafo. Valga recordar que la organización por párrafos es de Nicolini.

Vico, G., Ciencia nueva. Trad. Rocío de la Villa, Madrid, Tecnos, 2006, 147.

SN, 330. 
notado, que «Vico es el filósofo de los orígenes de la especie humana, el inventor de un método genético» ${ }^{4}$.

Lo humano no es para Vico una realidad estática sino un proceso de creación cultural y de artificios que se produce históricamente en el ámbito de las instituciones humanas y el mundo civil ${ }^{5}$, porque el ser humano se hace a sí mismo y a su entorno. En este sentido, es evidente la decisión del autor de considerar al hombre como un homo faber y al verum factum como una clave de interpretación privilegiada de lo humano y de su génesis. Como homo faber el ser humano se distingue por ser artífice de sí mismo y del mundo civil. Esta concepción es el punto de partida para la propuesta viquiana de establecer un principio epistemológico que asuma la relación íntima que hay entre lo humano y su hacer: el verum factum. Berlin define con gran claridad este principio: «podemos decir que conocemos auténticamente una cosa sí, y solo sí, conocemos por qué es y cómo es, o cómo llegó a ser lo que es, o qué se hizo para que fuera así» ${ }^{6}$. Esta formulación tiene como consecuencia el hecho de que el acceso al mundo civil, y a su origen, es posible gracias a que nos es dado comprender lo que seres humanos con mentes similares a las nuestras han hecho y cómo lo han hecho. Vico considera, entonces, que «el criterio y la regla de lo verdadero es haberlo hecho ${ }^{7}$ : se llega a conocer lo que podemos hacer.

En la búsqueda de los orígenes, el principio epistemológico del verum factum es fundamental pues se convierte en el rasero gracias al cual Vico logra establecer «una distinción crucial [para su propuesta] entre los orígenes sagrados y los comienzos gentiles e históricos $»^{8}$. Los orígenes sagrados están referidos a la creación del mundo del que Dios es «el primer hacedor», el principio de todo, incluido el ser humano ${ }^{9}$; los orígenes gentiles dan cuenta del hecho de que el ser humano, a la vez que es parte del mundo creado por Dios, compone y hace configurándose a sí mismo históricamente. A partir de esta distinción, el napolitano establece que sólo nos es posible conocer lo que mentes similares a las nuestras han hecho, y por tanto el camino epistemológico viable es el que se ocupa del mundo histórico hecho por los hombres; el mundo creado por Dios nos es desconocido por cuanto no lo hemos llevado a cabo. Así las cosas, la Ciencia nueva tiene como propósito transitar el camino cognoscitivo que le es posible: aquel que se ocupa del desarrollo de lo humano, que comienza precisamente con su origen gentil.

Vico asume que esta indagación sobre lo hecho por los seres humanos, y sobre el modo en que se modifican a sí mismos y a su entorno, debe ser llevada

4 Lollini, M., «On Becoming Human: The Verum Factum Principle and Giambattista Vico's Humanism», en: MLN 127, The Johns Hopkins University Press, 2012, S 21.

5 Ib., SN 30.

6 Berlin, I., Vico y Herder, Catedra, Madrid, 2000, 46.

7 Vico, G., «La antiquísima sabiduría de los italianos», en: Obras, trad. Francisco Navarro Gómez, Anthropos, Barcelona, 2002, 139.

8 Lollini, op. cit., S 20.

9 «La antiquísima sabiduría de los italianos», 134. 
a cabo de dos maneras complementarias: por un lado, bajo una estructura conceptual y universal, la filosofía, y por otro lado, bajo una estructura histórico-empírica que no olvide la multiplicidad y el cambio, la filología. De esta manera, el napolitano resuelve tanto el problema de las unilateralidades de la razón abstracta de los filósofos como el del determinismo empírico de los filólogos ${ }^{10}$. Por tanto, la filosofía no puede actuar sola, sino que debe dedicarse a examinar la filología ${ }^{11}$, que es definida por el autor como «la doctrina de todas las cosas que dependen del arbitrio humano, como son todas las historias de las lenguas, de las costumbres y de los hechos tanto de la paz como de la guerra de los pueblos» ${ }^{12}$. La Ciencia nueva como «nueva arte crítica» es, por consiguiente, una teoría de la interpretación de los orígenes que supone una interacción constante entre filosofía y filología; dicha dinámica conlleva, necesariamente, sea una redefinición de la filosofía, sea una ampliación del campo de la acción de la filología. Tales transformaciones van dirigidas a repensar lo humano y a modificar el legado del Humanismo.

La originalidad de Vico consiste en darle curso a la tensión entre el Humanismo y la ciencia moderna. Esta tensión se articula [precisamente] a través de la compleja relación entre «filología» y «filosofía» que estructura la obra maestra de Vico: la Ciencia nueva ${ }^{13}$.

De esta tensión, jamás pacificada, resulta una nueva manera de concebir la racionalidad moderna. Este artículo se propone demostrar que tal renovación es indispensable para emprender la indagación sobre los orígenes de lo humano, pues este, como diría Verene, «descenso en la historia» ${ }^{14}$, que accede incluso a una protohistoria en la que no hay ya huellas documentales, obliga a Vico a idear un modo nuevo de aproximación del que no puede dar cuenta la razón moderna de corte cartesiano. La exigencia, entonces, es la de afinar y ajustar el modo de comprensión del mundo humano porque sólo así se llega a tener acceso a la historia desde sus remotos orígenes. Esto supone abandonar la idea de conocer sólo a través del entendimiento puro para alcanzar un tipo de racionalidad en la que la imaginación y la sensibilidad tomen parte, sólo así el estudioso podrá hacerse cargo de las primeras expresiones de los seres humanos que son fruto de fuertes emociones y de una robusta imaginación. Esta racionalidad, que se presenta como inclusiva, se llevará a cabo en el ejercicio conjunto de una filología, que en este texto llamaremos ampliada, y de una filosofía, metafísica de la mente, que articulará ontogénesis y filogénesis. La dinámica de estos dos saberes constituirá el método genético con el que Vico

10 Cacciatore, G., «Un'idea di moderna certezza. La filosofia di Vico tra ermeneutica e filosofia», en: Vico nella storia della filologia, Alfredo Guida Editore, Nápoles, 2004, 180.

11 SN, 7.

$12 \mathrm{SN}, 7$.

13 Lollini, M., «Humanism, Posthumanism, and Neohumanism: Introductorry Essay», en: Annali d'italianistica 26, Arizon State University, 2008, 18-19.

14 Verene, D. P., Knowledge of Things Human and Divine. Vico's New Science and Finnegans Wake, Yale Universiy Press, 2003, 3. 
se hará cargo de esta humanidad lejana y primitiva. De una forma paralela, esta comprensión de los orígenes, le ayudará a consolidar una mordaz crítica al racionalismo de su época y a su modo concebir lo humano. En un círculo virtuoso Vico terminará afinando su forma de comprensión conducido por el tema mismo que se ha propuesto atender: la historia de los primeros habitantes del mundo y sus expresiones.

\section{La AMPLIACión DE LA FILOLOGÍa A LA LUZ DEL PARTO DE GEMELAS: ORALIDAD Y ESCRITURA}

Vico abre la Ciencia nueva con un grabado que representa la «Idea de la obra». Su intención es mostrarle al lector una síntesis visual de su texto, se trata de un recurso de carácter mnemotécnico. No es este el contexto para abundar en las explicaciones que Vico da de la imagen que abre la Ciencia nueva, lo que interesa para el tema aquí tratado son las palabras finales de esta primera parte de su gran obra: «las tinieblas en el fondo del grabado son la materia de esta Ciencia, incierta, informe, oscura $»^{15}$. El objetivo que moverá al autor será, pues, iluminar esta oscuridad que cubre los orígenes de la humanidad.

La decisión viquiana de remontarse a los orígenes oscuros lo lleva a proponer una ciencia que se ocupa de una historia de la humanidad que tiene como objeto "no sólo los periodos "fáciles" de los hechos humanos, para los cuales existen testimonios ciertos [...] sino también los periodos más remotos envueltos en las fábulas y las leyendas de los cuales hay testimonios inciertos ${ }^{16}$. El napolitano pone su atención, entonces, en una antigüedad no documentada que, según su propio decir, se hallaba cronológicamente en medio de dos historias: la Historia Sagrada (que narra cosas verdaderas) y las primeras historias de los griegos y los romanos (primeras fuentes atendibles de las cosas verdaderas), es decir, entre la historia sagrada narrada por Moisés y la historia de los gentiles narrada por Homero y Numa que se dio 1300 años después ${ }^{17}$.

Según Vico, este vacío histórico ha sido llenado de forma equivocada por la mayoría de los doctos. La razón de esto queda expuesta en uno de los axiomas generales de la Ciencia nueva en el que se denuncia que la fuente inagotable de los errores cometidos, con respecto a los principios de la humanidad, obedece a que «los hombres no pueden hacerse a la idea de las cosas lejanas y no conocidas, [sino que] las consideran según las cosas que les son conocidas y presentes ${ }^{18}$. Esto quiere decir que las refinadas mentes de los modernos les transfieren las características de sus propias mentes a aquellas de los seres

$15 \mathrm{SN}, 41$.

16 Rossi, P., I segni del tempo. Storia della Terra e storia delle nazioni da Hooke a Vico, Feltrinelli, Milán, 1979, 220.

17 Rossi, P., I segni del tempo. Storia della Terra e storia delle nazioni da Hooke a Vico, Feltrinelli, Milán, 1979, 213.

$18 \mathrm{SN}, 122$. 
humanos de la antigüedad oscura. Vico quiere eliminar este prejuicio que se ha convertido en «la fuente inagotable de los errores aceptados por naciones enteras y por todos los doctos respecto al principio de la humanidad ${ }^{19}$, y por ello se pone en la tarea de desmontar este principio interpretativo en razón de que elimina la distancia temporal que hay respecto de las cosas lejanas y no conocidas; censura a los doctos y a su vanidad que consiste en pensar que «lo que ellos saben sea tan antiguo como el mundo $»^{20}$ : una actitud de este tipo, imposibilita entender la diferencia de mentalidad entre los tiempos modernos y estas primeras naciones.

Gracias a la herencia de la tradición humanista, el napolitano está en posesión de una conciencia histórica definida que le permite romper el prejuicio de los doctos y acercarse al pasado sólo después de hacer las cuentas con la distancia temporal que lo separa de este; de hecho, los humanistas descubren los clásicos porque los separan y distinguen de sí mismos ${ }^{21}$, en este sentido, Vico conviene con la crítica que los filólogos del humanismo le hacen a los filólogos antiguos quienes, corrigiendo los textos del pasado y registrando los mitos cívicos, veían su propio tiempo como una continuación del pasado que estudiaban $^{22}$. Una filología genuinamente histórica es el legado que Vico asume del humanismo italiano. El napolitano sigue los pasos de Valla, quien «mostraba cómo el filólogo necesitaba imaginar la gama de problemas a los que, años atrás, se veía enfrentado el escriba ${ }^{23}$. De esta forma, el filólogo aceptaba la perspectiva del anacronismo y se convertía en un estudioso que daba cuenta del ángulo histórico de la visión ${ }^{24}$.

Vico se acoge a la conciencia histórica que desde Petrarca la filología humanista exhibe, sin embargo, no la deja intacta dado que el proyecto de una ciencia nueva exige una transformación de dicha disciplina para poder cumplir su objetivo. Hay que comenzar, por tanto, con la claridad de que el napolitano no busca solo interpretar textos escritos (escritura alfabética), sino que dada la especificidad misma de su indagación por los orígenes de las naciones, tiene que vérselas también con diversas formas de expresión anteriores al advenimiento de la escritura en sentido propio: desde el gesto hasta la escritura misma pasando por monedas, jeroglíficos, escudos, enseñas, entre otras cosas. Dicha decisión teórica le supone a Vico ampliar el ámbito de acción de los filólogos redefiniéndolos como «los gramáticos, historiadores, críticos, que se ocupan del conocimiento de las lenguas y de los hechos de los pueblos, tanto en la casa,

\footnotetext{
19 SN, 123.

20 SN, 127.

21 GARIN, E., L'umanesimo italiano, Laterza, Roma, 1975, 21.

22 Turner, J., The forgotten origins of modern humanities, Princeton University Press, Princeton, 2014, 43.

23 Turner, op. cit., 42.

$24 \mathrm{Ib}, 42$.
} 
como son las costumbres y las leyes, cuanto fuera, como son las guerras, las paces, las alianzas, los viajes, los comercios» ${ }^{25}$.

La ampliación del campo de estudio de los filólogos está en consonancia con el hecho de que Vico vuelca su atención sobre los tiempos en la que no hay documentos escritos y, en consecuencia, no hay una historia en sentido propio; el autor de la Ciencia nueva debe atender, por tanto, a las expresiones de los pobladores de esta "antiquísima antigüedad» y preguntarse por el modo de interpretarlas. En la búsqueda por esta clave de acceso a las manifestaciones de los antiguos, Vico formula una hipótesis que es revolucionaria para su tiempo y que determinará su modo de comprenderlas: el hecho de que oralidad y escritura nacen simultáneamente en lo que Vico llama, de forma metafórica, un parto de gemelas. Así, ya desde las primeras páginas de la Ciencia nueva, en «Idea de la obra», el napolitano advierte que las monstruosas explicaciones de los filólogos deben ser atribuidas al hecho de que «los filólogos han creído que en las naciones habían nacido antes las lenguas, después las letras; cuando [...] nacieron gemelas y caminaron a la vez, en sus tres especies, las letras con las lenguas» ${ }^{26}$.

Vico asume que la tradición de la filología se equivoca al considerar que el lenguaje fónico precede a la escritura. Para él letras y lenguas nacen en un parto gemelar. Con el fin de comprender esta propuesta, resulta útil traer a colación algunos elementos de la lectura que de este pasaje hace uno de los estudiosos más agudos sobre el tema: Jürgen Trabant. El pensador alemán considera que Vico asume una posición que contrasta con el fonocentrismo propio de la filosofía occidental, esto lo hace dando lugar a la propuesta del parto de gemelas: la lengua articulada y la escritura. Ahora bien, al igual que en un parto gemelar en el mundo natural, Vico le atribuye sólo una pequeña primacía al momento gráfico en el sentido de que es el primer gemelo que sale de la matriz ${ }^{27}$. Este parto gemelar lleva consigo una redefinición de las lenguas y las letras que da lugar a la ampliación de su espectro de aplicación. En este orden de ideas, «por letras Vico no entiende las letras del alfabeto, sino toda producción escrita, la semiosis visual en general [...]. Por tanto, escribir para Vico no significa "escribir" en el sentido de un dispositivo de registro para el lenguaje, sino producción de signos visuales en general, independientemente del lenguaje» ${ }^{28}$; de acuerdo con esta formulación, los gestos y los actos formarían también parte de la escritura. Por tanto, la escritura incluiría tanto los actos y los gestos, escritura del cuerpo, como la escritura alfabética propiamente dicha.

Del mismo modo que el «escribir originario» del cuerpo se desarrolla hasta devenir escritura en sentido estricto, el cantar se despliega en el hablar,

$25 \mathrm{SN}, 139$.

26 SN, 33

27 Trabant, J., La scienza nuova dei Segni antichi. La sematologia di Vico, Laterza, Bari, 1996.

28 Trabant, J., Cenni e voci. Saggi di sematologia, trad. Elisabetta Proverbio, Arte tipografica editrice, Nápoles, 2007, 51. 
ampliando así el espectro de la otra gemela: la lengua ${ }^{29}$. Hay un desarrollo análogo entre la escritura y la lengua. De este modo, estos seres que inicialmente son mudos y «se expresan mediante actos y cuerpos que guardan relaciones naturales con las ideas que se quieren significar ${ }^{30}$, a la vez, rompiendo el silencio, «sacan sus sonidos informes cantando y también los tartamudos cantando sueltan la lengua para pronunciar», todo ello "[guardando] una relación natural con las ideas que quieren significar ${ }^{31}$. El hecho de romper con el silencio sugiere que en el parto gemelar la primera gemela nacida sea la escritura, acto seguido nace la lengua. Pero la distancia temporal es reducida.

Vico sitúa cronológicamente este parto gemelar en el espacio temporal que se da entre la historia sagrada y las primeras historias de lo griegos y los romanos. Como se ha dicho, el napolitano pretende «llenar el vacío» entre las dos épocas y, para hacerlo, establece un evento que le funciona como bisagra entre una y otra y le permite hablar del nacimiento de unos gigantes salvajes, «bestioni», y de su eventual proceso de civilización: el Diluvio universal. Esta catástrofe natural, narrada en la Biblia, le da la posibilidad de ubicar cronológicamente a estos primeros pobladores sin prescindir del todo de las Sagradas Escrituras. Cien años después del diluvio unos pocos «bestioni» que deambulaban por la selva elevaron los ojos al cielo y atónitos y asustados por los truenos expresaron sus violentísimas pasiones; aullando y gimiendo interpretaron los signos del cielo dando lugar a las primitivas formas de «escritura» a través del gesto y del lenguaje a través del grito. Para Vico, este evento de carácter religioso es la primera manifestación de humanidad.

Los pobladores posdiluvianos desahogan sus violentas pasiones a través del canto expresando tanto su dolor como su alegría ${ }^{32}$. Sus gritos tienen un carácter onomatopéyico que imita fonéticamente los ruidos del mundo. Vico lo explica con un caso emblemático: el surgimiento de Júpiter, el primero de los pensamientos-palabras humanas y universal poético.

Al mismo tiempo que se formó el carácter divino de Júpiter, que fue el primero de todos los pensamientos humanos del mundo gentil, comenzó a la vez a formarse la lengua articulada con la onomatopeya, con la que todavía observamos que se explican felizmente los niños. Y primeramente aquel Júpiter fue llamado por los latinos por el estruendo del trueno, primero «Ious»; por el silbido del rayo fue llamado por los griegos «Zeus» ${ }^{33}$.

Trabant ve en esta imitación fónica del rumor del trueno la primera palabra, sonido-imagen, del dios tronante Júpiter. El gesto del dios, su furia, es imitada con la voz y este fonema se convierte en el primer carácter poético Ious que es el punto de partida de Ious que significa derecho. De este modo, «en la mímesis

\footnotetext{
29 Trabant, Cenni e voci, 52.

$30 \mathrm{SN}, 225$.

$31 \mathrm{SN}, 228$.

$32 \mathrm{SN}, 230$.

$33 \mathrm{SN}, 447$.
} 
de la naturaleza se encuentra lo común entre voz y gesto» ${ }^{34}$. La producción de signos es para Vico un hecho tanto somático como pragmático esto se hace evidente en el caso de Júpiter, en el momento de nombrar al dios tronante hay una conformación de sentido en torno a un acontecimiento como el trueno, que da lugar a acciones y gritos: es el origen del primer acto religioso y de la primera ley. Tanto el uno como la otra, son fruto del miedo al trueno, que no es otra cosa que el grito de Júpiter legislador. La comunidad nace con la religión que es hija de un miedo y un respeto originario. El gesto del dios es «leído» como palabra escrita en el cielo; los gestos y los gritos de estos primeros pobladores dan comienzo a la oralidad: en el ámbito de la oralidad y de la escritura nace la primera fábula que es Zeus.

Ahora bien, de este temor inicial que lleva a los seres gigantescos y brutales a nombrar a Ious, no hay rastro material. La ausencia de huellas obliga a la conjetura pues se trata de una antiquísima antigüedad que, según el mismo napolitano, está cubierta de una «densa noche de tinieblas» ${ }^{35}$. Vico constata esta carencia y la afronta con la claridad de que la filología que se amplía a épocas en las que no hay huellas documentales no puede obrar sola, será necesario articularla con una metafísica de la mente, sólo así se logrará dar cuenta de esta lejana época. A continuación, se explicará en que consiste este trabajo conjunto y cuál es su dinámica dentro de la Ciencia nueva.

\section{LA METAFísica DE LA MENTE: «ENTRAR» EN LA MENTE DE LOS PRIMITIVOS}

En la primera parte de la «Metafísica poética», Vico pone de presente la diferencia entre las mentes de estos primeros pobladores robustos y de violentísimas pasiones con la mente de los seres humanos de los tiempos de reflexión y abstracción.

Pero, como ahora (debido a la naturaleza de nuestras mentes humanas, incluso en el mismo vulgo están demasiado alejadas de los sentidos con tantas abstracciones de las que están llenas las lenguas cuantos vocablos abstractos, y se han hecho demasiado sutiles, y casi espiritualizadas con la práctica de los números, hasta el punto que vulgarmente saben contar y escribir) [...]; igualmente, ahora nos es naturalmente negado poder entrar en la vasta imaginación de aquellos primeros hombres cuyas mentes eran en absoluto abstractas, ni afinadas para nada, ni en nada espiritualizadas, ya que estaban totalmente inmersas en los sentidos, rendidas a las pasiones, enterradas en los cuerpos: de ahí que antes dijéramos mas arriba que apenas se pueden entender, ni imaginar en absoluto, como pensaron los primeros hombres que fundaron la humanidad del mundo gentil ${ }^{36}$.

\footnotetext{
34 Trabant, Cenni e voci, 54.

$35 \mathrm{SN}, 331$.

$36 \mathrm{SN}, 378$.
} 
Esta declaración sobre la imposibilidad de entender o imaginar cómo pensaron los primeros seres humanos es un modo de mostrar al lector la tarea ingente a la que se ve enfrentado. La Ciencia nueva es el fruto de este empeño. De hecho, en múltiples ocasiones para aludir a estos orígenes de las naciones, Vico usa términos que, como ya se ha visto, sugieren la dificultad de acercarse a ellos, así en «De los Principios» se refiere a una «densa noche de tinieblas» que cubre esta antiquísima antigüedad ${ }^{37}$. El autor presupone una escasa visibilidad que en ningún momento lo disuade de su intento, de hecho, la Ciencia nueva tiene el propósito de sortear la dificultad y de encontrar el modo de acceder a estos tiempos lejanos y oscuros, pero, sobre todo, a las mentes de los hombres que los poblaron. Retomando la metáfora de la visión, se pregunta por la manera en que es posible aclarar, iluminar, comprender la mente de estos robustos $\mathrm{y}$ violentos seres.

Correlativo a la poca iluminación que hay en relación a estos tiempos remotos está el esfuerzo por verlos, por acercarse a ellos de algún modo y, por consiguiente, la cuestión de las condiciones de visibilidad con respecto a un evento tan lejano en el tiempo como es el momento en el que los primeros pobladores iniciaron a pensar de forma humana. En suma, la gran dificultad a la que se enfrenta Vico en la Ciencia nueva es la inconmensurabilidad entre las mentes de épocas distintas, para sortearla concibe nuevas herramientas interpretativas que reconfiguran tanto la filología como la filosofía y la relación entre ellas. Como ya se ha visto, la filología ampliada es condición necesaria pero no suficiente para acceder a los orígenes, por tanto, para el napolitano, las conclusiones a las que llega son viables sí y solo sí se articula con una metafísica de la mente en la que el individuo transpone su experiencia de individuo a la experiencia de la especie.

Ya se ha aclarado que la clave epistemológica ideada por Vico, para comprender el devenir de lo humano, es el verum factum que supone que podemos comprender aquello que hacemos y por ello tenemos un acceso a aquello que los hombres han hecho a lo largo del tiempo. Este principio se fundamente en un conocimiento que se da, según palabras de Berlin, desde el interior, pero ¿qué quiere decir esto? Significa que el hecho de que «este mundo civil ha sido hecho ciertamente por los hombres» supone que los principios de ese hacer pueden y deben ser hallados en las modificaciones de nuestra propia mente humana" ${ }^{\prime 8}$, es decir, se llega a comprender el origen de la comunidad, porque los seres que pretenden acceder a él tienen mentes similares a la de aquellos que conforman dicha comunidad primera. Esto da lugar a una metafísica de la mente.

En otras palabras, no hay modo de adentrarse en la conformación del mundo civil sin comprender lo qué es tener una mente, es decir, "de qué manera [los seres humanos de los orígenes] responde a los estímulos, y en qué se

37 SN, 331.

38 SN, 331. 
distingue este proceder del seguimiento de reglas o de la actuación conforme a un principio ${ }^{39}$, o incluso, sin comprender qué es odiar, amar, qué es ser infantil o crítico, ingenuo o dominante entre muchas otras actitudes. Parafraseando a Berlin, sólo se puede comprender cuando se trata de seres semejantes: los seres angélicos a los seres angélicos, los seres humanos a los seres humanos ${ }^{40}$; esto no significa que la comprensión de esas mentes sea transparente, jamás lo llegará a ser. Hay que contar con eso, entre otras cosas por la gran distancia temporal que existe en relación con ellas.

En este orden de ideas, la apuesta de Vico es por lograr tener acceso a las mentes de los primeros hombres a pesar de la distancia y las diferencias que separan al estudioso moderno de ellas. Este acceso debe darse desde el interior para cubrir, de algún modo, la distancia desde la semejanza de las mentes, más no desde la identidad ${ }^{41}$. La manera que Vico encuentra para llevar a cabo su objetivo está ligada precisamente a este conocimiento desde el interior, al hecho de que todo ser humano fue niño alguna vez, en algún momento gritó porque tenía hambre, imitó los sonidos de su entorno y paulatinamente aprendió a relacionarse con los otros y a seguir instrucciones. El desarrollo cronológico de la vida de cada ser humano es análogo al desarrollo de la especie. En razón de lo anterior, Vico propone apelar a la memoria y a la imaginación como facultades que le permiten una cierta comprensión de la mente de aquellos seres. La metafísica de la mente propuesta por el napolitano supone que, para hacerse cargo del modo de funcionamiento de las mentes de estos primeros pobladores, se debe llevar a cabo un ejercicio de comprensión en el que la propia experiencia ontogenética es fundamental.

Ahora, como ya se ha dicho, esta comprensión de los seres humanos primitivos desde lo interior no es suficiente por sí sola debe complementarse con la dimensión empírica de la que está a cargo la filología. Sólo la colaboración de las dos disciplinas podrá disipar las tinieblas que cubren los primeros tiempos.

\section{FILOGÉNESIS Y ONTOGÉNESIS: LA POSIBILIDAD DE ARTICULAR FILOLOGÍA Y FILOSOFÍA}

Para entender la articulación entre la filología y la filosofía es oportuno acudir a una suerte de explicación que Vico hace de lo humano en las páginas finales de la Ciencia nueva:

En resumen —no siendo el hombre, propiamente, sino mente, cuerpo y habla, y estando el habla como colocada en medio de la mente y el cuerpo-, lo cierto en torno a lo justo comenzó con los tiempos mudos del cuerpo;

39 BERLIN, op. cit., 67.

40 Ibid.

41 Perullo, N., Bestie e bestioni. Il problema dell'animale in Vico, Alfredo Guida editore, Nápoles, 2002, 28. 
después una vez descubiertas las lenguas que se llaman articuladas, pasó a las ideas ciertas, o fórmulas de palabras ${ }^{42}$.

Se refiere Vico al habla como colocada en medio de la mente y el cuerpo con los que forma una unidad que es indisoluble, no hay mente sin habla y sin cuerpo. En una suerte de linguistic turn el napolitano asume que el ejercicio interpretativo desde el interior, propio de esta metafísica de la mente, tendrá que completarse con la dimensión corporal y expresiva que se manifiesta en signos de diferente índole. La metafísica, por tanto, no podrá actuar sola, sino que le será necesario servirse de la filología como la disciplina que versa sobre la dimensión empírica y semiótica del quehacer humano. Sólo gracias a esta dialéctica entre filología y filosofía, Vico logra avanzar en el estudio de las mentes primitivas y la manera como inauguran la vida en común.

Se ha visto cómo la ingeniosa formulación de que el habla está en medio de la mente y el cuerpo, le permite a Vico articular la metafísica de la mente con el estudio de las lenguas, es decir, con la filología que da cuenta de las expresiones empíricas de los seres humanos. De esta forma, queda claro cómo el desarrollo de las lenguas y de las instituciones no es más sino la expresión de diferentes mentalidades humanas en cada época. Desde esta perspectiva teórica Vico identifica tres tipos de mentalidades, tres edades posdiluvianas que corresponden al desarrollo ontogenético del individuo, estas son: la edad de los dioses, de los héroes y de los hombres. Estas tres etapas van desde las lenguas mudas hasta las lenguas articuladas, desde el pensar salvaje de los gigantes hasta el pensar sofisticado de los hombres. Cada una tiene una forma de expresión distinta, una lengua distinta que se diferencia de las otras en razón de los siguientes factores: contexto socio-cultural, campo del discurso, materialidad de los signos, proporción entre el elemento visual y el elemento acústico ${ }^{43}$.

En la primera lengua, de los dioses, el campo del discurso está dado por la experiencia de lo sagrado y en ella predominan los gestos, pues «fue casi toda muda y poco articulada» ${ }^{44}$; en la segunda lengua, de los héroes, «los significantes son caracteres heroicos y empresas heroicas, es decir semata: representaciones gráfico simbólicas [...] con temáticas relativas a la guerra» ${ }^{45}$. Esta lengua es una «mezcla entre articulada y muda» ${ }^{46}$. En la tercera lengua, propia de la edad de los hombres, el discurso se amplía y el lenguaje «está dirigido fundamentalmente a la comunicación de algo a alguien más bien que a la cognición y a la formación del pensamiento» ${ }^{47}$. Esta lengua es en su mayoría articulada y poco muda ${ }^{48}$.

\section{$42 \quad \mathrm{SN}, 1045$.}

43 Zagarella, «Le tre spezie di lingue nella Scienza nuova di Vico: interpretazione diacrónica e funzionale», en: Laboratorio dell' ISPF, VI, 2009, 1/2 pp. 20-36.

44 SN, 32.

45 Zagarella, op. cit., 27.

$46 \mathrm{SN}, 446$.

47 ZagaRella, op. cit., 27.

$48 \mathrm{SN}, 446$. 
Para explicar el desarrollo de la lengua en estas tres etapas, Vico lleva a cabo una operación que Trabant describe de un modo efectivo: «sobre un funcionamiento sincrónico funcional del lenguaje [...] proyecta en una diacronía conjetural $»^{49}$, en otras palabras, el napolitano hace una conjetura sobre las tres lenguas, y su carácter diacrónico, a partir de un estudio del uso del lenguaje. Para entender adecuadamente esta proyección, y mostrar sus consecuencias, resulta útil ilustrarla con una digresión de Pennisi sobre expresión viquiana lingue mutole (lenguas mudas) ${ }^{50}$. El autor sugiere que con el fin de explicar las lenguas mudas es necesario abordarlas desde múltiples dimensiones: ontogenética, filogenética, pero también morfogenética y sociogenética. El estudioso pone de presente que Vico, al referirse a las lenguas mudas, lingue mutole, hace alusión a la ausencia de lengua articulada que caracteriza a los gigantes, bestioni, en los orígenes de la edad gentil. Esta condición de penuria lingüística, "propia de los neonatos de todas las épocas [...] [que] tiene[n] que ver con la evolución del individuo en general $\aleph^{51}$, es proyectada por Vico al mundo de los gigantes de modo que la dimensión ontogenética del desarrollo de los niños se proyecta en el origen de la especie. Adicionalmente, Pennisi sostiene que para poder reconstruir esta fase de la lengua muda Vico tiene que recurrir también a la dimensión morfogenética del lenguaje, alegando que para reconstruir esta fase mutola de las lenguas, que está a la base de la constitución del lenguaje, el napolitano no usa solamente el modo de expresión infantil sino además el de las personas afectas a alguna patología comunicativa: tartamudos o sordomu$\operatorname{dos}^{52}$. Finalmente, la acuñación de lingue mutole se pude ampliar a la historia de las lenguas deviniendo característico de cada época y sociedad. De este modo, mutola tiene que ver tanto con las especies y las clases de individuos generales y particulares como con las distintas sociedades y las etnias en las que se da un paso de la mudez a la voz.

En esta reflexión de Pennisi queda sentada que la penuria lingüística de los infantes, y las personas con alguna patología del lenguaje, son herramientas interpretativas para comprender la labilidad de los habitantes de los tiempos primeros. Parafraseando a Trabant: sobre el funcionamiento sincrónico funcional, propio de los niños y aquellos que tienen una patología del lenguaje, se proyecta en una diacronía conjetural que se despliega en el desarrollo lingüístico de la especie. Así, el interés de Vico recae en el tránsito tanto ontogenético como filogenético entre la mudez y la voz, entre las letras y las lenguas. El parto

49 Trabant, J., La scienza nuova dei segni antichi, Laterza, 1996, 53, citado en Roberta Martina Zagarella, Le tre spezie di lingue nella Scienza nuova di Vico: interpretazione diacrónica e funzionale, en «Laboratorio dell'ISPF», vi, 2009, 1/2, 29.

50 Véase SN, 434.

51 Zagarella, op.cit., 23. En su artículo Zagarella alude a los siguientes textos de A. Pennsini (es un apellido italiano: cf. http://web.tiscali.it/penni/ingenium.html), «L'ingenium e i segni muti», en: Ingenium propria hominis natura. Atti del Convegno Internazionale di Studi, Napoli, 22-24 maggio 1997, Liguori Editore, Nápoles, 2002, 281-294, 283-284, además, Vico e i segni muti, en: J. Trabant ed., Vico und die Zeichen, Narr, Tubinga, 1995, 179-195.

52 Zagarella, op. cit. 23, nota 20. 
gemelar se puede dar, por tanto, sea en el ámbito de la vida del infante como en el de la infancia de la especie. Por consiguiente, el paso de la mudez a la voz es comprendido en la dinámica entre una metafísica de la mente, que permite el tránsito entre la dimensión ontogenética y filogenética, y una filología ampliada gracias al parto gemelar de oralidad y escritura.

\section{UNA NUEVA COMPRENSIÓN DE LO HUMANO EN RAZÓN DE SUS ORÍGENES}

Tomar en consideración tanto el punto de vista ontogenético como filogenético, implica un complejo ejercicio de interpretación que involucra no sólo la dimensión racional sino también la sensible, la emocional y la imaginaria. Esto en razón de que el individuo transpone el recuerdo de una época como la infancia, en la que predomina la imaginación y la sensibilidad, a la infancia misma de la especie. De ese modo, el estudioso, a partir de un ejercicio interpretativo que involucra la imaginación y la memoria, se aproxima a los primeros tiempos en los que hay de por medio emociones que tienen que ver con la carencia y el miedo y que se convierten en el punto de giro hacia la búsqueda de la expresión y del sentido. De algún modo, lo anterior supone que ninguna de las expresiones humanas desaparece completamente con el «proceso de civilización» ya que conviven en toda época manifestaciones emotivas como el gesto, el grito, el canto y el habla, en diferentes proporciones y de diversas maneras. Sin embargo, el refinamiento de la mente ha hecho que los seres humanos hayan fijado su atención sólo en la razón y sus procesos dejando de lado las facultades cercanas al cuerpo. El napolitano denuncia este paulatino refinamiento y lo asume como la causa principal de lo que él llama una barbarie de la razón.

Es así que Vico considera que el estudioso debe partir por denunciar la vanidad de los doctos que, con su la pretensión de acceder a las mentes de los primeros seres humanos desde el refinamiento de su razón, son ciegos frente a la diferencia de los primeros pobladores. Seguido a su denuncia, el napolitano propone el ejercicio de interpretación arriba expuesto en el que se hace necesaria una articulación entre una metafísica de la mente con una filología ampliada, todo en aras de lograr comprender a estos seres de tiempos lejanos sin transponerles categorías meramente racionales. Este ejercicio interpretativo tiene una doble consecuencia: la primera es de carácter metodológico y se traduce en el hecho de que, para lograr acceder al modo como las primitivas sociedades se relacionan con el mundo, se hace necesaria una suerte de «reforma del entendimiento", esto implica que el método mismo exige un ejercitarse en un uso sintético del entendimiento. Solo así, parafraseando a Vico, se llegará a ver el todo de cada cosa, y verlo todo junto. Eso significa intelligere, y solo así usamos verdaderamente el entendimiento ${ }^{53}$. La segunda es de carácter crítico

53 VIco, «La antíquisima sabiduría de los italianos», 133-134. 
en tanto que el acceso a los orígenes pone en cuestión lo que Merleau-Ponty ${ }^{54}$ llama el hombre consumado cartesiano que se comprende a sí mismo y a los otros sólo desde la dimensión de la razón. En fin, no hay una racionalidad consumada ni la habrá jamás porque la universalidad ostensiva de la penuria existencial y lingüística de los primeros hombres está presente en todos los tiempos. Esta es uno de los descubrimientos más importantes de la Ciencia nueva.

\section{BibLIOGRAFíA}

Berlin, I. (2000). Vico y Herder. Madrid: Catedra.

Cacciatore, G. (2004). «Un'idea di moderna certezza. La filosofia di Vico tra ermeneutica e filosofia», en Vico nella storia della filologia. Nápoles: Alfredo Guida Editore.

Garin, E. (1975). L'umanesimo italiano. Roma: Laterza.

Lollini, M. (2012). «On Becoming Human: The Verum Factum Principle and Giambattista Vico's Humanism», MLN 127, The Johns Hopkins University Press.

Lollini, M. (2008). «Humanism, Posthumanism, and Neohumanism: Introductory Essay», en: Annali d'italianistica 26, Arizon State University, p. 18-19.

Merleau-Ponty, M. (2002). El mundo de la percepción. Siete conferencias. Buenos Aires: Fondo de Cultura Económica.

Pennisi, A. (1995). «Vico e i segni muti», en: J. Trabant ed, Vico und die Zeichen, Narr, Tubinga.

Pennisi, A. (2002). "L’ingenium e i segni muti», Ingenium propria hominis natura. Atti del Convegno Internazionale di Studi (Napoli, 22-24 mayo 1997). Nápoles: Liguori Editore.

Perullo, N. (2002). Bestie e bestioni. Il problema dell'animale in Vico. Nápoles: Alfredo Guida editore.

Rossi, P. (1979). I segni del tempo. Storia della Terra e storia delle nazioni da Hooke a Vico. Milán: Feltrinelli.

Trabant, J. (1996). La scienza nuova dei Segni antichi. La sematologia di Vico. Bari: Laterza.

Trabant, J. (2007). Cenni e voci. Saggi di sematologia vichiana. Nápoles: Arte tipográfica editrice.

Turner, J. (2014). The forgotten origins of modern humanities. Princeton: Princeton University Press.

Verene, D. P. (2003). Knowledge of Things Human and Divine. Vico's New Science and Finnegans Wake, Yale Universiy Press.

Vico, G. (2002).«La antiquísima sabiduría de los italianos», en: Obras, trad. Francisco Navarro Gómez. Barcelona: Anthropos.

Vico, G. (2006). Ciencia nueva. Madrid: Tecnos.

54 Merleau-Ponty, M., El mundo de la percepción. Siete conferencias, Fondo de Cultura Económica, Buenos Aires, 2002, 38. «¿Por qué tantos escritores muestran indiferencia para con los animales, los niños, los locos, los primitivos? Porque están persuadidos de que hay un hombre consumado, destinado a ser 'dueño y poseedor' de la naturaleza, como decía Descartes $[\ldots] »$. 
Vico, G. (201). La Scienza nuova. Le tre edizioni del 1725, 1730 y 1744, M. Sanna y V. Vitiello eds., Bompiani, Milán.

Zagarella (2009). «Le tre spezie di lingue nella Scienza nuova di Vico: interpretazione diacrónica e funzionale», en: Laboratorio dell' ISPF, VI, 1/2 pp. 20-36,

Pontificia Universidad Javeriana, Bogotá

Anna Maria Brigante Rovida

Facultad de Filosofía

anna.brigante@javeriana.edu.co

anna.brigante@gmail.com

[Artículo aprobado para publicar en enero de 2019] 